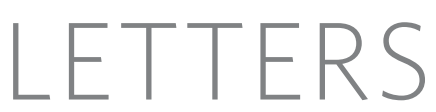

\title{
Short-circuiting of the overturning circulation in the Antarctic Circumpolar Current
}

\author{
Alberto C. Naveira Garabato ${ }^{1}$, David P. Stevens ${ }^{2}$, Andrew J. Watson ${ }^{3} \&$ Wolfgang Roether ${ }^{4}$
}

The oceanic overturning circulation has a central role in the Earth's climate system and in biogeochemical cycling ${ }^{1,2}$, as it transports heat, carbon and nutrients around the globe and regulates their storage in the deep ocean. Mixing processes in the Antarctic Circumpolar Current are key to this circulation, because they control the rate at which water sinking at high latitudes returns to the surface in the Southern Ocean ${ }^{3-8}$. Yet estimates of the rates of these processes and of the upwelling that they induce are poorly constrained by observations. Here we take advantage of a natural tracer-release experiment-an injection of mantle helium from hydrothermal vents into the Circumpolar Current near Drake Passage - to measure the rates of mixing and upwelling in the current's intermediate layers over a sector that spans nearly onetenth of its circumpolar path. Dispersion of the tracer reveals rapid upwelling along density surfaces and intense mixing across density surfaces, both occurring at rates that are an order of magnitude greater than rates implicit in models of the average Southern Ocean overturning ${ }^{4-8}$. These findings support the view that deep-water pathways along and across density surfaces intensify and intertwine as the Antarctic Circumpolar Current flows over complex ocean-floor topography, giving rise to a short circuit of the overturning circulation in these regions.

The Southern Ocean has been identified as a possible crossroads of two contrasting paradigms for how mixing processes mediate the powering of the overturning circulation by winds and tides. In the longest-standing view ${ }^{10}$, the overturning is powered by turbulent diapycnal mixing below the permanent pycnocline, which often results from internal wave instabilities and is enhanced near topography. In an alternative mode $^{5-8,11,12}$, the overturning is chiefly driven by mesoscale eddies transporting water masses along the steep isopycnals of the Antarctic Circumpolar Current (ACC), with diapycnal transformations induced by air-sea-ice interaction in the mixed layer. A new proposition ${ }^{13}$ suggests that the wind work sustaining the vigorous Southern Ocean eddy field may also support intense internal wave activity and turbulent mixing in ACC regions of complex topography. If so, the two proposed solutions to the oceanmixing problem could be interdependent, and it might no longer be appropriate to consider them in isolation.

The most insightful description of how the overturning circulation is closed by upwelling in the ACC has been provided by twodimensional models grounded in residual-mean theory ${ }^{3-8}$. These models endorse the second ocean-mixing paradigm above. They portray the zonal-average Southern Ocean overturning as a residual circulation arising from the imbalance between a wind-driven Ekman cell, which tends to tilt isopycnals, and an opposing eddydriven cell acting to flatten isopycnals. Implicit are the notions that eddy-induced isopycnal mixing acts down property gradients with a diffusivity of $500-1,500 \mathrm{~m}^{2} \mathrm{~s}^{-1}$, and that diapycnal mixing in the ocean interior is negligible with a diffusivity of $\sim 10^{-5} \mathrm{~m}^{2} \mathrm{~s}^{-1}$. In this overturning closure, eddies drive upwelling along the middepth ACC isopycnals with a vertical velocity of $\sim 30 \mathrm{~m} \mathrm{yr}^{-1}$ $\left(\sim 10^{-6} \mathrm{~ms}^{-1}\right)$, while sinking at a similar rate ensues in the Southern Ocean north and south of the ACC. Transitions between different levels of the overturning occur at the Southern Ocean surface or at depth in the oceans to the north, so relatively long transit paths in the deep ocean are implied for water parcels participating in the circulation. This fundamental result of residual-mean models excludes any interdependence between the two proposed solutions to the ocean-mixing problem, but appears at odds with indirect estimates of turbulent diapycnal mixing rates in the $\mathrm{ACC}^{13,14}$.

We put the residual-mean models to the test by quantifying the rates of mixing and upwelling in the southwest Atlantic sector of the ACC (Fig. 1) from the spreading of a conservative natural tracer. The tracer is primordial ${ }^{3} \mathrm{He}$, which enters the circulation in hydrothermal fluids issued by submarine volcanoes. In the southeast Pacific, a ${ }^{3} \mathrm{He}$-rich plume emanating from the East Pacific Rise flows southward at a depth of $\sim 2,500 \mathrm{~m}$ along the South American margin and is injected into the ${ }^{3} \mathrm{He}$-poor ACC upstream of Drake Passage ${ }^{9}$. As it crosses the Scotia Sea, the plume dilutes and spreads owing to upwelling and mixing with surrounding waters, at rates that we can estimate from its dispersal. This exercise requires knowledge of the tracer distribution before and after the mixing event, as well as of the pre-injection background tracer field ${ }^{15}$. The latter is defined (Fig. 2) using observations from the western and central South Pacific (see Supplementary Notes).

Figure 3 shows primordial ${ }^{3} \mathrm{He}\left({ }^{3} \mathrm{He}_{\mathrm{na}}\right.$, see Supplementary Notes) as the ACC enters and leaves the Scotia Sea. In Drake Passage, the ${ }^{3} \mathrm{He}$-rich plume stands out as a two-core maximum (with ${ }^{3} \mathrm{He}_{\mathrm{na}}>$ $0.6 \mathrm{fmol} \mathrm{kg}{ }^{-1}$ ) superimposed on a broader tongue of abovebackground concentrations. The plume is oriented along the southward-shoaling isopycnals and is centred near the boundary between the upper and lower cells that compose the Southern Ocean overturning ${ }^{5}$. On leaving the region, the plume has been homogenized substantially by mixing, and ${ }^{3} \mathrm{He}_{\mathrm{na}} \approx 0.44 \mathrm{fmol} \mathrm{kg}^{-1}$ at its core. We confine our calculation of mixing and upwelling rates to the ACC zone unaffected by interaction with ${ }^{3} \mathrm{He}$-poor Weddell Sea waters found at the southern edge of the study region, so as to preserve the problem's tractability (see Supplementary Notes). The control volume of the calculation lies within the Upper Circumpolar Deep Water (UCDW), and extends $\sim 1,500 \mathrm{~km}$ along the ACC, $\sim 1,000 \mathrm{~km}$ across and $\sim 1,000$ m vertically.

The cross-stream isopycnal mixing of the tracer may be characterized with a diffusivity $K_{\downarrow}$. We estimate (see Methods) that the regional-average $K_{\psi}$ is $1,840 \pm 440 \mathrm{~m}^{2} \mathrm{~s}^{-1}$, with a considerably lower value of $360 \pm 330 \mathrm{~m}^{2} \mathrm{~s}^{-1}$ in the ACC frontal jets, which are partial isopycnal mixing barriers. These estimates may be biased low by up to 


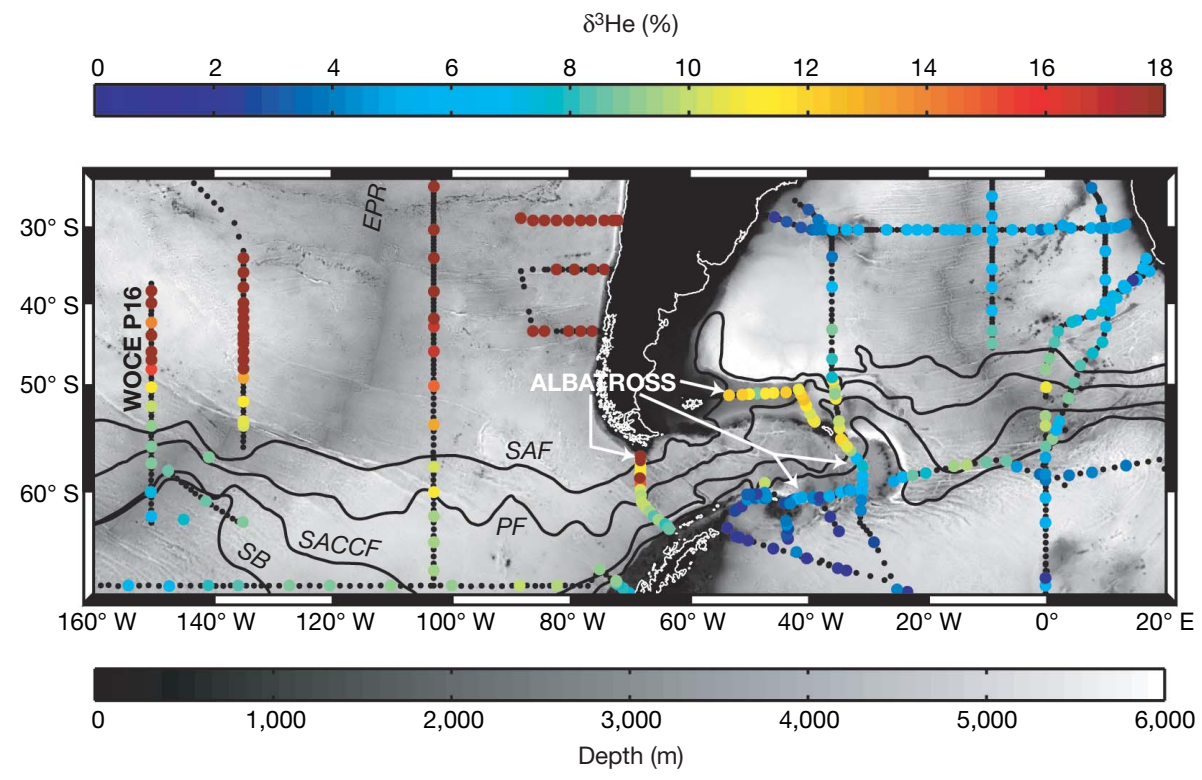

Figure 1 | Large-scale distribution of primordial ${ }^{3} \mathrm{He}$ in the deep Southeast Pacific and Southwest Atlantic. Topography is indicated by the grey shading. Station positions of hydrographic transects during which He parameters were measured are marked by the black dots, with the coloured circles showing $\delta^{3} \mathrm{He}$ on the neutral density ${ }^{31} \gamma^{n}=27.98 \mathrm{~kg} \mathrm{~m}^{-3}$ surface. The ALBATROSS and WOCE P16 sections, central to this study, are labelled. Climatological

$\sim 800 \mathrm{~m}^{2} \mathrm{~s}^{-1}$ and $\sim 300 \mathrm{~m}^{2} \mathrm{~s}^{-1}$, respectively (see Supplementary Notes). The diagnosed diffusivities are broadly compatible with those implicated in residual-mean descriptions of the Southern Ocean overturning. They also endorse previous indirect estimates of subsurface cross-stream isopycnal diffusivities in the ACC, which suggest globally peaking values of $200-1,000 \mathrm{~m}^{2} \mathrm{~s}^{-1}$ in the ACC pycnocline ${ }^{16-18}$. However, when compared to these, our high regionalaverage $K_{\psi}$ hints at an intensification of eddy-driven isopycnal mixing in the Scotia Sea relative to ACC-mean conditions.

Mesoscale eddies have an advective role too. The eddy-induced flow is deemed by residual-mean models to be the primary driver of UCDW upwelling along ACC isopycnals. This is because UCDW is generally shallower than topographic obstacles in the ACC's path, and deep-water upwelling associated with the Ekman cell must by dynamical necessity be confined to below the crests of those obstacles $^{19}$. In the context of the dispersing plume, we expect eddy-driven upwelling of UCDW to promote a poleward translation of the tracer's centre of mass. This is what we observe (Fig. 3).

Whereas in Drake Passage the centre of mass lies north of the Polar Front in the $17-38 \mathrm{~Sv}$ streamfunction range (see Supplementary Notes), in the outflow region it is positioned at $\sim 80 \mathrm{~Sv}$ between two branches of the Polar Front. As much as $90 \%$ of the tracer sits north of this streamline in Drake Passage. The implication is that UCDW parcels typically cross one-third of the ACC's width in flowing through the Scotia Sea, upwelling at a rate of $w_{\psi}{ }^{*} \approx$ $330 \pm 110 \mathrm{~m} \mathrm{yr}^{-1}$ (see Methods) that may be biased high by up to $\sim 75 \mathrm{~m} \mathrm{yr}^{-1}$ (see Supplementary Notes). Because the presence of South America prevents deep water of northern origin from entering the ACC, the isopycnal upwelling of UCDW is compensated by vertical convergence at the northern boundary. This is manifested in the shoaling of UCDW isopycnals near that boundary as the ACC crosses the study region (Fig. 3). The upwelling rate associated with the observed displacement, averaging $160 \mathrm{~m}$ in the control layer, is $260 \mathrm{~m} \mathrm{yr}^{-1}$, consistent with our estimate of $w_{\psi}{ }^{*}$. Thus, eddy-driven isopycnal upwelling of UCDW in the region occurs at a remarkably high rate that is an order of magnitude greater than predicted by residual-mean models of the zonal-average overturning. This result concurs with the findings of several eddy-permitting ocean models, which suggest that deep-water upwelling across the ACC is localized positions of the ACC fronts (SAF, Subantarctic Front; PF, Polar Front; SACCF, Southern ACC Front) and its southern boundary (SB) are indicated by the black lines. We note the gradual penetration of the ${ }^{3} \mathrm{He}$-rich water from the subtropical Pacific into the ACC east of $\sim 120^{\circ} \mathrm{W}$, reaching its maximum expression in Drake Passage. The southern edge of the East Pacific Rise, which is the chief source of the ${ }^{3} \mathrm{He}$ in our study region, is labelled EPR.

in a few atypical regions of complex topography ${ }^{20-22}$ such as that under study here. Further, it is dynamically consistent with our $K_{\psi}$ estimates (see Supplementary Notes).

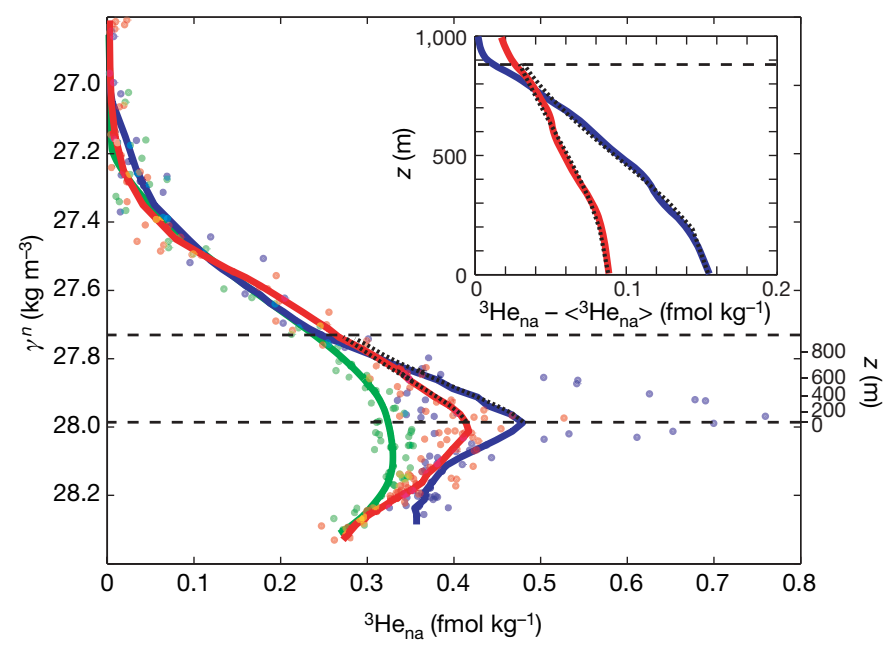

Figure 2 | Downstream evolution of the primordial ${ }^{3} \mathrm{He}$ distribution in density coordinates. Primordial ${ }^{3} \mathrm{He}\left({ }^{3} \mathrm{He}_{\text {na }}\right)$ and $\gamma^{n}$ of samples collected in the ACC north of the SACCF, at three sets of locations: $\sim 145^{\circ} \mathrm{E}$ (WOCE S3) and $150^{\circ} \mathrm{W}$ (WOCE P16, see Fig. 1), green circles; ALBATROSS Drake

Passage transect, blue circles; and ALBATROSS Scotia Sea outflow section, red circles. The green line defines $<{ }^{3} \mathrm{He}_{\text {na }}>$, the pre-injection ${ }^{3} \mathrm{He}_{\mathrm{na}}$, and is a spline fit to the green circles. The blue and red lines show $\int\left({ }^{3} \mathrm{He} e_{n a}\right) \mathrm{d} l / \int \mathrm{d} l$ for Drake Passage and the Scotia Sea outflow, respectively, where $\mathrm{d} l$ is a length increment and the integral is taken along isopycnals for the ACC equatorward of $\psi_{\mathrm{s}}$ (see Fig. 3). The dotted lines represent weighted-leastsquares normal-distribution fits to $\int\left({ }^{3} \mathrm{He}_{\mathrm{na}}-<^{3} \mathrm{He}_{\mathrm{na}}>\right) \mathrm{d} l / \int \mathrm{d} l$ in Drake Passage and the Scotia Sea outflow (see Supplementary Notes), with ${ }^{3} \mathrm{He}_{\mathrm{na}}>$ added back. The dashed lines bound the $\gamma^{n}$ range entering the least-squares fits. The mean height of $\gamma^{n}$ surfaces above the plume axis $(z)$ is marked in the right axis. The inset displays the measured and fitted tracer profiles (same line type and colour coding as in main panel) with the background subtracted as a function of $z$. Only the segment of the profiles within the $\gamma^{n}$ range entering the calculation is shown. 
The diapycnal mixing of ${ }^{3} \mathrm{He}$ reveals itself as a broadening of the tracer distribution in density space (Fig. 2). We represent the diapycnal mixing rate with a diffusivity $K_{\rho}$, estimated (see Methods) as $(3.2 \pm 2.3) \times 10^{-4} \mathrm{~m}^{2} \mathrm{~s}^{-1}$, a conspicuously high value exceeding open-ocean background diffusivities by an order of magnitude ${ }^{15}$. Our direct determination of the regional-mean $K_{\rho}$ agrees with indirect estimates of the turbulent mixing rate associated with internal wave breaking in the same ACC sector ${ }^{13}$, suggesting that this process dominates the diapycnal mixing of UCDW averaged over the large study area $\left(\sim 10^{12} \mathrm{~m}^{2}\right)$. An indirect estimate of the diapycnal upwelling rate $w_{\rho}^{*}$ (see Methods) indicates that diapycnal upwelling associated with this vigorous mixing is between one and two orders of magnitude weaker than regional-mean isopycnal upwelling, and comparable to the zonal-average isopycnal upwelling. This substantiates the eddies' dominance in driving UCDW upwelling in the Southern Ocean, and unveils the existence of a significant diapycnal pathway directed on average from the denser to the lighter layers of the ACC.

Our determination of the rates of mixing and upwelling averaged over a substantial sector of the ACC lends credence to some fundamental aspects of the residual-mean paradigm of the overturning circulation but challenges others. In the first category, mesoscale eddies are observed to mix tracers isopycnally at roughly the predicted rate and to play a leading part in promoting UCDW upwelling along density surfaces. Unexpectedly, this eddy-driven isopycnal upwelling is much too rapid to fit residual-mean model predictions for the zonal-average overturning and occurs in conjunction with intensified mid-depth diapycnal mixing and upwelling. The coexistence of these two extraordinary phenomena in a specific region suggests that they may be physically related, and exposure of the deep-reaching ACC eddy flows to the complex topography of the southwest Atlantic ${ }^{19}$ provides various potential linking mechanisms ${ }^{23-25}$. A common theme to these is that for eddies to drive intense upwelling they must undergo a vigorous cycle of growth and decay ${ }^{26}$. In the residual-mean paradigm, eddy growth is attributed to the welldocumented action of baroclinic instability but no consideration is given to the decay mechanism.

We propose that the required damping of the eddy field may be provided in part by generation of internal waves as eddy flows impinge on topography. Subsequent upward wave propagation and breaking can explain the observed presence of high internal wave energy levels ${ }^{13}$ and intense diapycnal mixing at mid-depth in our study region. The plausibility of this eddy damping mechanism is upheld by the broad quantitative correspondence between the wind work on the ACC $\left(E_{\text {mean }} \approx 10 \mathrm{~mW} \mathrm{~m}^{-2}\right.$ ) (ref. 27$)$; the rate at which baroclinic instability transfers energy from the ACC mean flow to its eddy field in our study region ( $E_{\text {eddy }} \approx 10 \mathrm{~mW} \mathrm{~m}^{-2}$, see Methods); the rate at which eddy energy is fluxed downward as ACC eddies grow, following an inverse energy cascade $\left(E_{\text {inv-casc }} \approx 5 \mathrm{~mW} \mathrm{~m}^{-2}\right.$ ) (ref. 28 ); and the rate of energy dissipation by internal wave breaking as the ACC crosses the Scotia Sea $\left(E_{\text {turb }} \approx 5 \mathrm{~mW} \mathrm{~m}^{-2}\right.$ ) (ref. 13). This mechanistic link between isopycnal upwelling and diapycnal mixing may be important to the representation of eddies in climate-scale ocean models, as it presents a

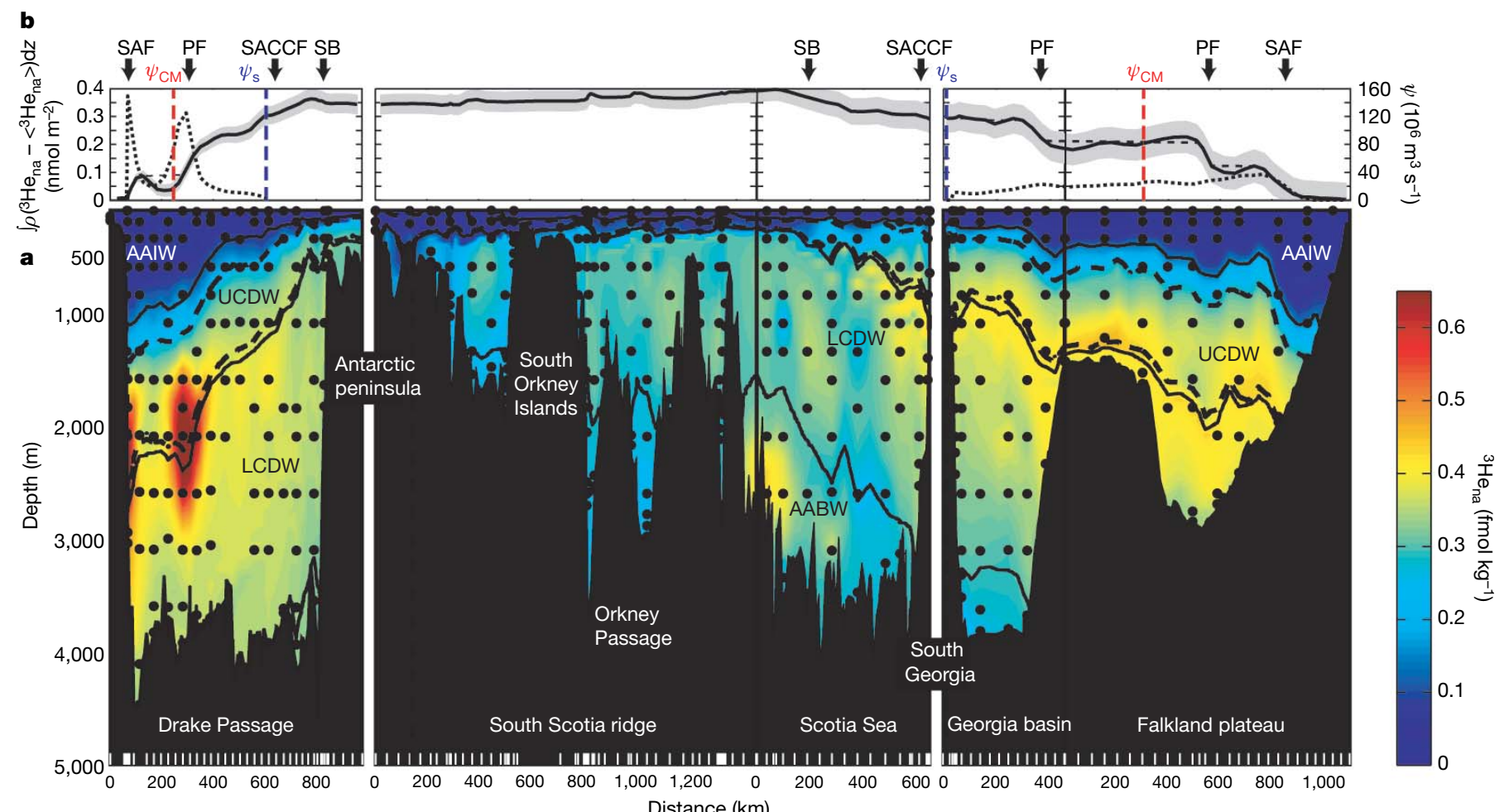

Distance $(\mathrm{km})$

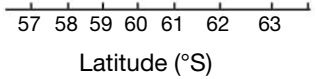

$$
\begin{aligned}
& 5452 \quad 5048 \\
& \text { Longitude ( } \left.{ }^{\circ} \mathrm{W}\right)
\end{aligned}
$$

Figure 3 | Distribution of primordial ${ }^{3} \mathrm{He}$ and streamfunction along the Scotia Sea rim. a, Vertical section of ${ }^{3} \mathrm{He}_{\text {na }}$ (colours) following the ALBATROSS track (Fig. 1). Sample positions are shown by black dots. Major water masses of the Southern Ocean are indicated (AAIW, Antarctic Intermediate Water; AABW, Antarctic Bottom Water), their $\gamma^{n}$ bounds defined by the $27.55,28.0$ and $28.26 \mathrm{~kg} \mathrm{~m}^{-3}$ surfaces (solid black lines). Other $\gamma^{n}$ surfaces $\left(27.73\right.$ and $\left.27.98 \mathrm{~kg} \mathrm{~m}^{-3}\right)$ used in this study are shown by the dashed black lines. Topographic features are labelled and station positions indicated at the base of the topography. b, Vertical integral, between the 27.73 and $28.0 \mathrm{~kg} \mathrm{~m}^{-3} \gamma^{n}$ surfaces, of ${ }^{3} \mathrm{He}_{\text {na }}$ anomaly (that is, with $\left.<^{3} \mathrm{He}_{\mathrm{na}}\right\rangle$ subtracted, dotted black line). $\left\langle{ }^{3} \mathrm{He}_{\mathrm{na}}\right\rangle$ is defined in Fig. 2.

\section{$\begin{array}{llll}59 & 58 & 57 & 56\end{array}$ \\ Latitude ( $\left.{ }^{\circ} \mathrm{S}\right)$}

The dashed red lines labelled $\psi_{\mathrm{CM}}$ mark the position of the centre of mass of the vertically integrated tracer anomaly in Drake Passage and the outflow region. The solid black line shows the full-depth volume transport streamfunction $\psi$ of an inverse model solution ${ }^{32}$ in $\mathrm{Sv}\left(1 \mathrm{~Sv}=10^{6} \mathrm{~m}^{3} \mathrm{~s}^{-1}\right)$, with the grey shading indicating its uncertainty (one s.d. of the error in the inverse model solution). The dashed black line displays a monotonic functional approximation to $\psi$ used in the calculation of $K_{\psi}$ and $w_{\psi}{ }^{*}$ (see Supplementary Notes). The southern boundary of the $K_{\psi}$ and $w_{\psi}{ }^{*}$ calculation is marked by the dashed blue line, labelled $\psi_{\mathrm{s}}$. Positions of the ACC fronts and its southern boundary are indicated above panel $\mathbf{b}$. 
remedy to the unphysical violation of energy conservation in the prevalent parameterization of baroclinic instability ${ }^{29}$.

In fitting this energetically consistent sequence of physical processes, our findings back the emergence of a revised overturning circulation paradigm in which isopycnal and diapycnal deep-water pathways intensify and intertwine as the ACC flows over rough topography. In these sites, mid-depth waters straddling the boundary between the upper and lower cells of the Southern Ocean overturning can rapidly short-circuit their circulation through the deep ocean by both flowing swiftly along isopycnals and transiting across isopycnals between the downwelling and upwelling limbs of the overturning. This rapid short-circuiting of the overturning circulation raises the mean rate of ventilation of the deep Southern Ocean, and must significantly lessen its capability to store and distribute tracers to the oceans further north. In this light, the outcome of our tracerrelease experiment suggests that a dedicated investigation of the coupling between isopycnal and diapycnal mixing in the ACC may be a leap forward in understanding the driving of the overturning circulation and its wider linkages over climatic timescales.

\section{METHODS}

Calculation of the cross-stream isopycnal diffusivity $K_{\psi}$. We calculate the cross-stream isopycnal diffusivity as $K_{\psi}=\Delta \sigma_{\psi}{ }^{2} /(2 \Delta t)$ (ref. 15). Here, $\sigma_{\psi}{ }^{2}$ is the mean-square cross-stream tracer displacement relative to the centre of mass, the cross-stream direction is defined as normal to the full-depth volume transport streamfunction $\psi, t$ is time, and $\Delta$ denotes an increase (in any variable) between Drake Passage and the outflow region. We obtain two different estimates of $\Delta \sigma_{\psi}{ }^{2}=(7.20 \pm 1.10) \times 10^{4} \mathrm{~km}^{2}$ and $\Delta \sigma_{\psi}{ }^{2}=(1.40 \pm 1.25) \times 10^{4} \mathrm{~km}^{2}$ from the isopycnal spreading of the tracer, corresponding to two distinct definitions of the cross-stream coordinate (see Supplementary Notes). The first of these characterizes area-averaged isopycnal mixing conditions in the study region, whereas the second is representative of ACC frontal jet environments. We evaluate $\Delta t$ as $227 \pm 42$ days by reference to a suite of subsurface floats crossing the Scotia Sea ${ }^{16}$ (see Supplementary Notes). Combining our estimates of $\Delta \sigma_{\psi}{ }^{2}$ and $\Delta t$ yields a regional-average $K_{\psi}$ of $1,840 \pm 440 \mathrm{~m}^{2} \mathrm{~s}^{-1}$, with a considerably lower value of $360 \pm 330 \mathrm{~m}^{2} \mathrm{~s}^{-1}$ in the frontal jets.

Calculation of the isopycnal upwelling rate $w_{\psi}{ }^{*}$. We calculate the rate of upwelling characterizing the observed residual circulation as $w_{\psi}^{*}=$ $\Delta \psi_{\mathrm{CM}} \times L \times s_{\rho} /\left(\psi_{\mathrm{s}} \times \Delta t\right)$ (see Supplementary Notes for a derivation), where $\Delta \psi_{\mathrm{CM}} \approx 40 \mathrm{~Sv}$ is the downstream increase in the streamfunction coordinate of the tracer's centre of mass, $\psi_{s}=120 \mathrm{~Sv}$ denotes the ACC transport at the southern boundary of the control volume, $L \approx 1,000 \mathrm{~km}$ is the regional-average width of the ACC equatorward of $\psi_{\mathrm{s}}$, and $s_{\rho} \approx 10^{-3}$ defines the mean slope of isopycnals in the ACC. Substituting these values in the above expression, we obtain $w_{\psi}{ }^{*} \approx 330 \pm 110 \mathrm{~m} \mathrm{yr}^{-1}$.

Calculation of the diapycnal diffusivity $K_{\boldsymbol{\rho}}$. We calculate the diapycnal diffusivity as $K_{\rho}=\Delta \sigma_{\rho}^{2} /(2 \Delta t)$ (ref. 30), where $\sigma_{\rho}^{2}$ is the mean-square diapycnal displacement relative to the plume axis. We estimate that $\Delta \sigma_{\rho}{ }^{2}=$ $(1.27 \pm 0.88) \times 10^{4} \mathrm{~m}^{2}$ (see Supplementary Notes), yielding $K_{\rho}=(3.2 \pm 2.3)$ $\times 10^{-4} \mathrm{~m}^{2} \mathrm{~s}^{-1}$.

Calculation of the diapycnal upwelling rate $w_{\rho}^{*}$. We estimate the diapycnal upwelling rate by applying a one-dimensional diapycnal advection-diffusion buoyancy balance $\left(w_{\rho}^{*}=N^{-2} \times \partial\left(K_{\rho} \times N^{2}\right) / \partial z\right.$, where $N^{2}=-(g / \rho) \times \partial \rho / \partial z$ denotes the squared buoyancy frequency, $g$ is gravity and $\rho$ is the potential density) to indirectly estimated in situ profiles of $K_{\rho}$ and $N^{2}$ in the region ${ }^{13}$. The diagnosed $w_{\rho}{ }^{*}$ increases from $\sim 3 \mathrm{~m} \mathrm{yr}^{-1}$ in the shallower classes of UCDW to $\sim 30 \mathrm{~m} \mathrm{yr}^{-1}$ in the Lower Circumpolar Deep Water (LCDW).

Calculation of eddy energy transfer rate $E_{\text {eddy }}$. We quantify the rate at which baroclinic instability transfers potential energy from the ACC mean flow to its eddy field in the study region, using the expression $E_{\text {eddy }} \approx \rho \times w_{\psi}{ }^{*} \times N^{2} \times H^{2} \times \Delta \psi_{\mathrm{CM}} /$ $\psi_{\mathrm{s}} \approx 10 \mathrm{~mW} \mathrm{~m}^{-2}$ (see Supplementary Notes for a derivation), where $H$ is the vertical extent of the control volume and we have used $\rho=1,030 \mathrm{~kg} \mathrm{~m}^{-3}, w_{\psi}{ }^{*} \approx$ $10^{-5} \mathrm{~m} \mathrm{~s}^{-1}, N^{2} \approx 3 \times 10^{-6} \mathrm{~s}^{-2}, H \approx 1,000 \mathrm{~m}, \Delta \psi_{\mathrm{CM}} \approx 40 \mathrm{~Sv}$ and $\psi_{\mathrm{s}}=120 \mathrm{~Sv}$.

\section{Received 21 December 2006; accepted 12 April 2007.}

1. Rahmstorf, S. Ocean circulation and climate during the past 120,000 years. Nature 419, 207-214 (2002).

2. Sarmiento, J. L., Gruber, N., Brzezinski, M. \& Dunne, J. P. High-latitude controls of thermocline nutrients and low latitude biological productivity. Nature 427, 56-60 (2004).

3. Marshall, D. Subduction of water masses in an eddying ocean. J. Mar. Res. 55, 201-222 (1997)
4. Gnanadesikan, A. A simple predictive model for the structure of the oceanic pycnocline. Science 283, 2077-2079 (1999).

5. Speer, K., Rintoul, S. R. \& Sloyan, B. The diabatic Deacon cell. J. Phys. Oceanogr. 30, 3212-3222 (2000).

6. Marshall, J. \& Radko, T. Residual-mean solutions for the Antarctic Circumpolar Current and its associated overturning circulation. J. Phys. Oceanogr. 33, 2341-2354 (2003)

7. Bryden, H. L. \& Cunningham, S. A. How wind forcing and air-sea heat exchange determine the meridional temperature gradient and stratification for the Antarctic Circumpolar Current. J. Geophys. Res. 108, 3275, doi:1029/2001/ JC001296 (2003).

8. Olbers, D. \& Visbeck, M. A model of the zonally averaged stratification and overturning in the Southern Ocean. J. Phys. Oceanogr. 35, 1190-1205 (2005).

9. Well, R., Roether, W. \& Stevens, D. P. An additional deep-water mass in Drake Passage as revealed by ${ }^{3} \mathrm{He}$ data. Deep-Sea Res. / 50, 1079-1098 (2003).

10. Wunsch, C.\& Ferrari, R. Vertical mixing, energy, and the general circulation of the oceans. Annu. Rev. Fluid Mech. 36, 281-314 (2004).

11. Toggweiler, J. R. \& Samuels, B. On the ocean's large-scale circulation near the limit of no vertical mixing. J. Phys. Oceanogr. 28, 1832-1852 (1998).

12. Webb, D. J. \& Suginohara, N. Vertical mixing in the ocean. Nature 409, 37 (2001).

13. Naveira Garabato, A. C., Polzin, K. L., King, B. A., Heywood, K. J. \& Visbeck, M. Widespread intense turbulent mixing in the Southern Ocean. Science 303, 210-213 (2004).

14. Kunze, E., Firing, E., Hummon, J. M., Chereskin, T. K. \& Thurnherr, A. M. Global abyssal mixing inferred from lowered ADCP shear and CTD strain profiles. J. Phys. Oceanogr. 36, 1553-1576 (2006).

15. Ledwell, J. R., Watson, A. J. \& Law, C. S. Mixing of a tracer in the pycnocline. J. Geophys. Res. 103, 21499-21529 (1998)

16. Gille, S. T. Float observations of the Southern Ocean: Part 2. Eddy fluxes. J. Phys. Oceanogr. 33, 1182-1196 (2003).

17. Stammer, D. On eddy characteristics, eddy transports, and mean flow properties. J. Phys. Oceanogr. 28, 727-739 (1998).

18. Ferreira, D., Marshall, J. \& Heimbach, P. Estimating eddy stresses by fitting dynamics to observations using a residual-mean ocean circulation model and its adjoint. J. Phys. Oceanogr. 35, 1891-1910 (2005).

19. Olbers, D., Borowski, D., Völker, C. \& Wolff, J.-O. The dynamical balance, transport and circulation of the Antarctic Circumpolar Current. Antarct. Sci. 16, 439-470 (2004).

20. MacCready, P. \& Rhines, P. B. Meridional transport across a zonal channel: Topographic localization. J. Phys. Oceanogr. 31, 1427-1439 (2001)

21. Lee, M.-M. \& Coward, A. C. Eddy mass transport in an eddy-permitting global ocean model. Ocean Model. 5, 249-266 (2003).

22. Hallberg, R. \& Gnanadesikan, A. The role of eddies in determining the structure and response of the wind-driven Southern Hemisphere overturning: Results from the MESO project. J. Phys. Oceanogr. 36, 2232-2252 (2006).

23. Aguilar, D. A. \& Sutherland, B. R. Internal wave generation from rough topography. Phys. Fluids 18, doi:10.1063/1.2214538 (2006).

24. Polzin, K. L. Subinertial finestructure on the continental slope / rise transition. J. Phys. Oceanogr. (submitted).

25. Sanson, L. Z. \& van Heijst, G. J. F. Ekman effects in a rotating flow over bottom topography. J. Fluid Mech. 471, 239-255 (2002).

26. Wilson, C. \& Williams, R. G. When are eddy tracer fluxes directed down gradient? J. Phys. Oceanogr. 36, 189-201 (2006).

27. Wunsch, C. The work done by the wind on the oceanic general circulation. J. Phys. Oceanogr. 28, 2332-2340 (1998).

28. Scott, R. B. \& Wang, F. Direct evidence of an oceanic inverse kinetic energy cascade from satellite altimetry. J. Phys. Oceanogr. 35, 1650-1666 (2005).

29. Tandon, A. \& Garrett, C. On a recent parameterization of mesoscale eddies. J. Phys. Oceanogr. 26, 406-411 (1996).

30. Ledwell, J. R., Watson, A. J. \& Law, C. S. Evidence for slow mixing across the pycnocline from an open-ocean tracer release experiment. Nature 364, 702-703 (1993)

31. Jackett, D. R. \& McDougall, T. J. A neutral density variable for the world's oceans. J. Phys. Oceanogr. 27, 237-263 (1997).

32. Naveira Garabato, A. C., Stevens, D. P. \& Heywood, K. J. Water mass conversion, fluxes and mixing in the Scotia Sea diagnosed by an inverse model. J. Phys. Oceanogr. 33, 2565-2587 (2003).

Supplementary Information is linked to the online version of the paper at www.nature.com/nature.

Acknowledgements A NERC Advanced Research Fellowship supported A.C.N.G. during the analysis and writing of this Letter. We gratefully acknowledge feedback from J. Ledwell and K. Polzin.

Author Contributions A.C.N.G. designed and conducted the analysis and wrote the letter. D.P.S. and A.J.W. discussed aspects of the methodology and results, and helped with the writing. W.R. provided many of the ${ }^{3} \mathrm{He}$ data and advised on their use.

Author Information Reprints and permissions information is available at www.nature.com/reprints. The authors declare no competing financial interests. Correspondence and requests for materials should be addressed to A.C.N.G. (acng@noc.soton.ac.uk). 